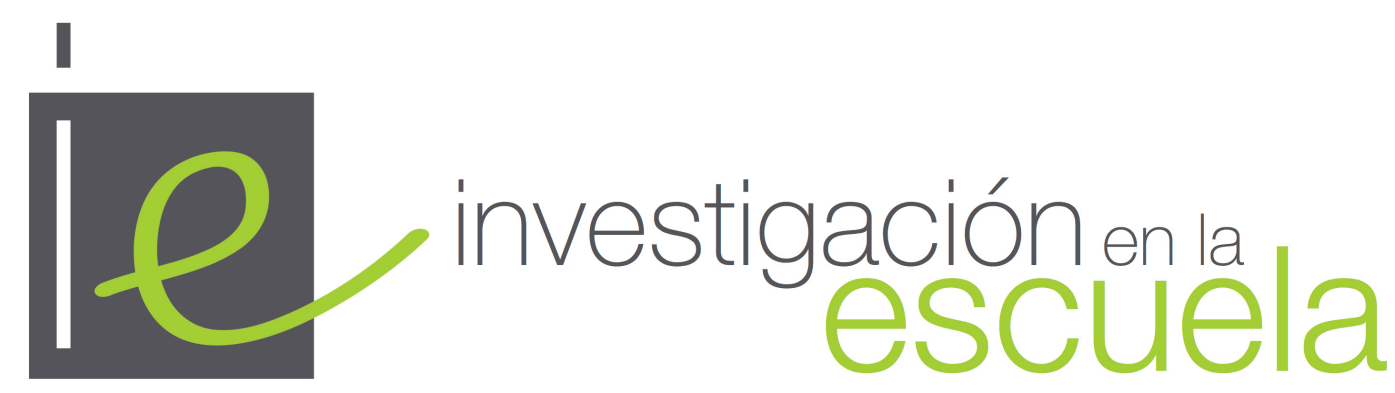

Revista internacional de investigación e innovación educativa

Número 93

28 de diciembre de 2017

ISSN 2443-9991

\title{
Las imágenes en los libros de texto: un análisis en el ámbito del ecosistema
}

\author{
Linda Arelis Silva Arias, Roque Jiménez Pérez \\ Universidad de Huelva \\ España
}

Citación: Silva Arias, L.A. y Jiménez Pérez, R. Las imágenes en los libros de texto: un análisis en el ámbito del ecosistema. Investigación en la escuela, 93, 58-75. Recuperado de:

http://www.investigacionenlaescuela.es/articulos/R93/R93-5

Resumen: En este estudio se analizan las imágenes de diversos libros de texto la enseñanza y aprendizaje del concepto de ecosistema. Para ello, se han utilizado cuatro libros de texto de las cuatro editoriales más empleadas en la Comunidad Autónoma de Andalucía. El análisis se realizó a través de una tabla de categorías validada que recoge las funciones de aquellas en la secuencia didáctica y en la iconicidad. Los resultados revelaron que solo algunas imágenes de los libros de texto presentan el nivel de iconicidad adecuado respecto a la función de la secuencia didáctica en la que aparecen, así como la tendencia en representarlas como complemento informativo del ecosistema. Tras este análisis destacamos la importancia de llevar a cabo procesos de alfabetización visual en los docentes y alumnos como coadyuvantes del uso idóneo de las imágenes para el desarrollo de la competencia meta-representativa.

Palabras clave: "Imágenes"; "ecosistema"; "libros de texto"; "iconicidad"; "alfabetización visual".

The images of textbooks: an analysis in the scope of the ecosystem

Abstract: In this study, we aim to analyse the images of textbooks and their usage in learning about and teaching the ecosystem. In order to do this, four textbooks of the four top-seller Editorials used in the Autonomous Community of Andalucía were studied. The analysis was conducted via a validated table of categories, which collects the functions of the above-mentioned images in the didactic sequence of iconicity. 
The results reveal that only some of the textbook images show an adequate level of iconicity with respect to the function of the didactic sequence in which they appear, as well as a clear tendency to represent the images as an informative complement of the ecosystem. After carrying out this analysis, we highlight the importance of developing teachers' and students' visual competences, as they are contributors to the appropriate usage of images in the development of the metarepresentative competence.

Key words: "Images"; "ecosystem"; "textbooks"; "iconicity"; "development of visual competence".

\section{Les images dans les livres scolaires: une analyse du domaine de l'écosystème}

Résumé: Dans cette étude sont analysés les images des livres scolaires pour l'usage de l'enseignement et de l'apprentissage de l'écosystème. Pour ce faire (ou à cette fin), ils ont utilisé quatre livres scolaires de quatre maisons d'édition les plus employés (ou connues) dans la communauté autonome d'Andalousie, l'analyse se réalisa à travers une table de catégories validée qui reprend les fonctions de celles-ci dans la séquence didactique et l'iconicité. Les résultats révélèrent que seulement quelques images des livres scolaires présentent le niveau d'iconicité adéquate concernant la fonction de la séquence didactique dans laquelle ils apparaissent, ainsi qu'une tendance marquée à représenter les images comme complément informatif de l'écosystème. Après cette analyse, nous soulignons l'importance de réaliser des procédés (ou processus) d'alphabétisation visuels sur les enseignants et élèves comme intervenants de l'usage idéal des images pour le développement de la concurrence méta-représentative/

Mostsclés: "images"; "écosystème”; "livres scolaires"; "iconicité"; "alphabétisation visuelle".

\section{Introducción}

Desde hace unas décadas se va abriendo camino en la Didáctica de las Ciencias Experimentales una línea de investigación acorde con los cambios sociales que se vienen produciendo en cuanto al uso progresivo de la imagen como medio de comunicación (Perales, 2006). Esta línea se ha ido diversificando a medida que crecía la intensidad investigadora. Así podemos establecer las siguientes categorías:

A) Según el canal de transmisión de la información: audiovisual (cine, televisión, videos, videojuegos, programas de simulación, hipermedia...); libro (libros de texto, comics...).

B) Según la tipología de imagen (estática, dinámica; fotografía, diagrama, dibujo...).

C) Según los destinarios (formación del profesorado, estudiantes de diferentes niveles educativos).

D) Según el contenido científico implicado (Física, Química, Biología, Histología....).

E) Según el objetivo de la investigación (caracterizar las imágenes, identificar dificultades, comparar métodos de enseñanza...).

Desde el punto de vista educativo esta cultura inmersa en las imágenes conlleva, por ejemplo, que para leer un diagrama científico altamente abstracto se requiera de habilidades muy diferentes a las precisas para leer imágenes cotidianas, como las fotografías del periódico. Esto es solo un indicador de la urgencia de iniciar procesos de alfabetización visual en las escuelas, facilitando la comprensión de representaciones icónicas de índole científico (Lowe, 2000).

Por otro lado, diferentes investigaciones han desvelado que los libros de texto continúan siendo los principales guiones de la puesta en escena que se vive continuamente en las aulas (Perales 
y Vilchez, 2012; López y Travé, 2013; Lazarowitz, 2014; Rodríguez, De las Heras, Romero y Cañal, 2014; Travé, Estepa y Del Val, 2017).

Dentro de esta perspectiva, ¿cómo iniciar procesos de alfabetización en la escuela con los estudiantes si los profesores no están formados para realizar lecturas icónicas? Al respecto, según Perales (2006), son escasas las referencias bibliográficas de que se dispone sobre el uso de estrategias para la enseñanza y el aprendizaje que se hayan basado en las imágenes y del papel que desempeñan las representaciones icónicas en el marco de la enseñanza de las ciencias. Debido a esto, se observa que el análisis de imágenes en los libros de texto desde el contexto del aula constituye un camino necesario para continuar ampliando esta línea de investigación.

Atendiendo a estas consideraciones, vamos a focalizar nuestro trabajo en juicios relacionados con el manejo de la iconografía contenida en los libros de texto puesto que, a pesar de que hoy día se ha incrementado en los estudiantes el consumismo y producción de todo tipo de imágenes (Perales y Vílchez, 2015), aún en las distintas investigaciones que se han realizado en educación en ciencias reciben una menor atención que el texto escrito y las actividades presentes en dichos materiales (López-Manjón y Postigo, 2016).

\section{Antecedentes teóricos}

Para nuestra investigación consideramos tres núcleos fundamentales que sustentan el estudio. En primer lugar, el análisis de las imágenes en libros de texto de Biología, en segundo lugar el ecosistema como concepto complejo con diversas formas en su construcción teórica y en las de abordarlos y, por otra parte, la sustentación de la alfabetización visual para el uso estratégico de las imágenes.

\section{Análisis de las imágenes en libros de texto de Biología}

Con el fin de mostrar organizadamente los precedentes investigadores en este tópico, en la Tabla I se han seleccionado y agrupado algunos artículos relativos a imágenes de libros de texto en el ámbito de la Biología, de acuerdo a distintas dimensiones de los mismos.

Tabla 1

Características de algunos estudios empíricos sobre imágenes en libros de texto de Biología

\begin{tabular}{|c|c|c|c|c|c|}
\hline Referencia & Tipo de imagen & Temática & $\begin{array}{l}\text { Nivel } \\
\text { educativo }\end{array}$ & $\begin{array}{l}\text { Tipo de } \\
\text { diseño }\end{array}$ & Instrumento \\
\hline $\begin{array}{l}\text { Artola, } \\
\text { Mayoral y } \\
\text { Benarroch } \\
(2016)\end{array}$ & $\begin{array}{l}\text { Representacio-nes } \\
\text { gráficas } \\
\text { cartesianas }\end{array}$ & $\begin{array}{l}\text { Biología de } \\
\text { poblaciones }\end{array}$ & $\begin{array}{l}\text { Educación } \\
\text { Secundaria }\end{array}$ & Descriptivo & $\begin{array}{l}\text { Categorización por } \\
\text { las investigadoras a } \\
\text { partir de } \\
\text { indicadores de } \\
\text { carácter semiótico }\end{array}$ \\
\hline $\begin{array}{l}\text { Mampel, } \\
\text { Cortés y } \\
\text { Alcalá (2015) }\end{array}$ & $\begin{array}{l}\text { Imágenes en } \\
\text { general }\end{array}$ & Dinosaurios & $\begin{array}{l}\text { Educación } \\
\text { Secundaria }\end{array}$ & Descriptivo & $\begin{array}{l}\text { Categorización por } \\
\text { los investigadores a } \\
\text { partir de una } \\
\text { taxonomía previa }\end{array}$ \\
\hline $\begin{array}{l}\text { López- } \\
\text { Manjón, A. y } \\
\text { Postigo, Y. }\end{array}$ & $\begin{array}{l}\text { Imágenes en } \\
\text { general }\end{array}$ & $\begin{array}{l}\text { Cuerpo } \\
\text { humano }\end{array}$ & $\begin{array}{l}\text { Educación } \\
\text { Primaria }\end{array}$ & Descriptivo & $\begin{array}{l}\text { Evolución por } \\
\text { niveles educativos, } \\
\text { categorización por }\end{array}$ \\
\hline
\end{tabular}


(2014) Ruppenthal y Chitolina (2014)

Catley, Novick y

Shade (2010)

Pozzer y Fotografías y imágenes, actividades prácticas y ejercicios Diagramas
Sistema Educación Descriptivo respiratorio Primaria texto asociado
Biología en general
Evolución Educación Descriptivo biológica Secundaria

Educación Descriptivo Secundaria los investigadores

Categorización por

los investigadores a partir de una taxonomía previa

Interpretación de diagramas por los estudiantes
Categorización por los investigadores

De la lectura de dicha tabla cabe apreciar que predomina el nivel educativo de Secundaria, un tipo de diseño descriptivo (análisis de contenido) y la utilización de instrumentos categoriales.

En este contexto nuestra investigación centra su interés en las imágenes presentes en un libro de texto sobre un tópico esencial, como es el de Ecosistema, resaltándose el lugar importante que ocupan aquellas para el desarrollo del proceso de enseñanza ya que, en ocasiones, los libros de texto pueden mostrar algunos diseños inadecuados que influyen negativamente en el aprendizaje de los estudiantes y sólo el docente es capaz de evitarlo. En este sentido, investigaciones como las de Álzate (1999) y Tapia y Arteaga (2012) desvelan que hay elementos en las imágenes que pueden tergiversar la interpretación que se haga de las mismas.

A este respecto coincidimos con Tapia y Arteaga (2012) en que el profesor es parte fundamental en los estudios de materiales curriculares, dado que es quien los vincula significativamente a sus clases; visto de este modo, es el docente el responsable de interactuar entre la ilustración y el alumno, brindando significado y orientando hacia los objetivos del tema.

En esta línea nos planteamos la siguiente pregunta de investigación: ¿Qué clase de imágenes podemos encontrarnos en los libros de texto en relación a su uso en la enseñanza y el aprendizaje del ecosistema?

Sobre la base de las ideas expuestas, surge el siguiente supuesto:

Las imágenes de los libros de texto, posiblemente, desvelen algunas inconsistencias didácticas que puedan afectar a su uso en el aula y al desarrollo de la competencia visual. En este sentido, nos hemos planteado el objetivo de analizar las imágenes de los libros de texto desde la función didáctica y la iconicidad que presentan en el ámbito del ecosistema.

\section{La enseñanza y el aprendizaje de un concepto complejo: el ecosistema}

El ecosistema está caracterizado por las diversas interacciones entre cada una de las partes que lo conforman y, según Del Carmen (2010) y Bravo y Jiménez-Aleixandre (2014), esta dinámica es compleja para ser enseñada y aprendida.

Una de las grandes dificultades a la que se enfrentan los estudiantes está relacionada precisamente con los procesos, ya que ocurren a grandes escalas físicas y temporales que no alcanzan a ser percibidas, omitiendo la realización de sus representaciones (Domingo-Martínez y JiménezPérez, 2014). 
En cuanto a las características de los ecosistemas, algunas investigaciones previas sobre dificultades de los alumnos indican que:

(1) La mayoría de los estudiantes suelen focalizar su interés en las relaciones tróficas y ocasionalmente con el hábitat (Rincón, 2011).

(2) Bravo y Jiménez-Aleixandre (2014) encontraron que en los estudiantes la noción teórica sobre flujo de energía es difícil de conectar con la disminución de biomasa y producción del ecosistema.

(3) En cuanto a la capacidad de los estudiantes de aplicar las ideas relativas al ciclo de la materia, en general aquellos mencionan la importancia de la descomposición pero no del reciclado de nutrientes al pasar de formas orgánicas a inorgánicas (García-Rodeja y Silva, 2014).

(4) Asimismo los estudiantes experimentan problemas de comprensión sobre la naturaleza y transformación de la energía, junto con el significado del flujo de energía en los ecosistemas ya mencionado (García-Rodeja y Silva, 2014).

(5) "Respecto a las bases epistemológicas que sustentan las ideas de los alumnos sobre la dinámica del ecosistema, diversos autores señalan que las ideas vitalistas principalmente, aunque también las teleológicas y las antropomórficas, emergen con fuerza en los discursos de los alumnos de básica secundaria” (Rincón, 2011, p. 90).

A ello habría que añadir la escasez de propuestas didácticas en las que se presente el ecosistema desde una visión sistémica y compleja de la dinámica del mismo, así como las relaciones entre complejidad, dinámica, estabilidad y diversidad en un ecosistema (Rincón, 2011).

$\mathrm{Al}$ respecto, se considera que la aplicación de situaciones reales fuera y dentro de la escuela requiere integrar conocimientos teóricos y prácticos (Lopes y Rocha, 2008; Bravo y JiménezAleixandre, 2010), aspectos que quizás favorezcan la superación de algunas de las dificultades que se presentan en la enseñanza del ecosistema.

En este contexto de dificultades en la enseñanza y el aprendizaje del concepto de ecosistema, así como de la masiva utilización de libros de texto para la enseñanza, libros con una alta carga de imágenes ocupando sus páginas, surge el interés de analizar en qué medida dichas imágenes pueden ayudar o no a la adquisición de un correcto aprendizaje del mismo.

\section{Las imágenes de los libros de texto como aproximación a la alfabetización visual}

Como anticipamos en el apartado anterior, el libro de texto ha sido, sigue siendo y muy posiblemente continuará siendo importante como herramienta pedagógica para los docentes (Lazarowitz, 2014); por tanto, debemos considerarlo como pieza clave dentro de esta investigación. Según Lee (2010), las imágenes están omnipresentes y han experimentado un incremento del 50\% por página, comparado con los textos que se utilizaban hace medio siglo. Por otro lado, las imágenes son reconocidas como un gran apoyo en la educación de las ciencias, dado que aclaran contenidos y a la vez entretienen (González, Vildósola y Gine, 2012), aunque también han sido criticadas (Lee, 2010). Una imagen es una forma particular de representación de la realidad y puede ser interpretada de manera diferente (Postigo y López, 2012); en este sentido resulta complejo abarcar todos los aspectos que puedan acontecer alrededor de ésta.

Sin embargo, a nivel de los libros de texto, pueden categorizarse en dos clases: (1) las que son facilitadoras del aprendizaje, ya que son consideradas más sencillas que las palabras, aunque el profesorado adolece habitualmente de estrategias centradas en su uso específico en el aula, contemplándolas como un simple complemento informativo; y (2) las que, por el contrario, no son 
tan facilitadoras del aprendizaje, acreditando que éstas no son tan fáciles de comprender, por lo que precisan de una adecuada intervención del profesor como mediador en su interpretación. Ante esto, se puede decir que la primera concepción es una de las más destacadas y nominada como "psicología popular" (Fanaro, Otero y Greca, 2005).

Aunque no es motivo de este trabajo, deberíamos señalar que, como alternativa a la situación (2), los profesores deberían estar dispuestos a elaborar sus propios materiales curriculares (Parcerisa, 1996), ya que de esta forma podrían eliminarse las tergiversaciones y contribuirían en otros campos, por ejemplo, al del desarrollo de competencias para la alfabetización visual y que como señalan Waldrip y Prain (2012) son indispensables para alcanzar la alfabetización científica, en nuestro caso, para el ecosistema.

En consonancia con lo dicho, resaltamos que la Asociación de bibliotecas universitarias y de investigación (ACRL, 2011, citada en Reyes, García y Mateus, 2017) propone los estándares de alfabetización visual en forma de competencias en la educación superior:

(1) Determinar la naturaleza y extensión de los materiales visuales necesarios; (2) encontrar y acceder a imágenes y medios visuales de manera efectiva y eficiente; (3) interpretar y analizar los significados de las imágenes y los medios visuales; (4) evaluar las imágenes y sus fuentes; (5) usar imágenes y medios visuales de manera efectiva; (6) diseñar y crear imágenes significativas y medios visuales; y (7) entender muchas de las cuestiones éticas, legales, sociales y económicas que rodean a la creación de estrategias basadas en el dibujo con sus propios estudiantes (p.3).

\section{Diseño de la investigación}

Los materiales analizados fueron los libros de texto para segundo curso de la ESO, "Ciencias de la Naturaleza 2", de las editoriales más empleadas en la provincia de Huelva: Anaya, S.M, Santillana y Vicens Vives; para efectos de codificación son nominadas Libro 1, 2, 3 y 4, respectivamente. Las imágenes analizadas corresponden a las unidades didácticas que tratan los ecosistemas en cada uno de los libros. La recogida de información se realizó a través de una plantilla que incluye: aspectos formales, como la editorial, el número de página que contiene las imágenes y aspectos didácticos, como la función didáctica que se asigna a las imágenes y la iconicidad de dichas ilustraciones.

Para el tratamiento de la información se ha utilizado la taxonomía de imágenes adaptada de Perales y Jiménez (2002) (ver Tabla 2). La sistematización de los datos se llevó a cabo a través de registros de las frecuencias de variables como unidades de análisis (UA). 
Tabla 2

Instrumento de análisis utilizado para las imágenes. Fuente: adaptado de Perales y Jiménez. (2002)

\begin{tabular}{|c|c|c|c|c|}
\hline Ámbito & Categorías & Variables & Descriptores & $\begin{array}{c}\text { Código } \\
\text { de las } \\
\text { variables }\end{array}$ \\
\hline \multirow{11}{*}{$\begin{array}{l}\text { I. } \\
\text { Taxonomía } \\
\text { de las } \\
\text { imágenes en } \\
\text { los libros de } \\
\text { texto }\end{array}$} & \multirow{7}{*}{$\begin{array}{l}\text { I.A. } \\
\text { Función de } \\
\text { la } \\
\text { secuencia } \\
\text { didáctica } \\
\text { en la que } \\
\text { aparecen } \\
\text { las } \\
\text { imágenes } \\
\text { en el libro } \\
\text { de texto }\end{array}$} & Evocación & $\begin{array}{l}\text { Se hace referencia a un hecho de la experiencia cotidiana o concepto que se supone conocido por el alumno. Ejemplo: "En el } \\
\text { desierto se necesita beber agua" }\end{array}$ & I.A1 \\
\hline & & Definición & $\begin{array}{l}\text { Se establece el significado de un término nuevo en su contexto teó rico. Ejemplo: "Un ecosistema es una comunidad de seres } \\
\text { vivos que interaccionan entre sí y con el medio en el que viven. }\end{array}$ & I.A2 \\
\hline & & Aplicación & $\begin{array}{l}\text { Es un ejemplo que extiende o consolida una definición. Ejemplo: "Cuando los zorros y los linces compiten por el mismo } \\
\text { alimento (conejos) hay una competencia interespecífica". }\end{array}$ & I.A3 \\
\hline & & Descripción & $\begin{array}{l}\text { Se refiere a hechos o sucesos no cotidianos que se suponen desconocidos por el lector y que permiten aportar un contexto } \\
\text { necesario. También se incluyen en esta categoría conceptos necesarios para el discurso principal pero que no pertenecen al } \\
\text { núcleo conceptual. Ejemplo: "En los ecosistemas hay dos tipos de componentes: los no vivos o abióticos, es decir, el medio } \\
\text { físico (agua y rocas...) y sus características (temperatura del agua, salinidad...) y los vivos o bióticos, como las plantas, } \\
\text { animales, el hombre etc". }\end{array}$ & I.A4 \\
\hline & & Interpretación & $\begin{array}{l}\text { Son pasajes explicativos en los que se utilizan los conceptos teóricos para describir las relaciones entre acontecimientos } \\
\text { experimentales Ejemplo: "El agua en un ecosistema puede ser dulce o salobre, por lo que se desarrolla una vegetación que } \\
\text { tolera cierta salinidad del medio." }\end{array}$ & I.A5 \\
\hline & & Problematización & $\begin{array}{l}\text { Se plantean interrogantes no retó ricos que no pueden resolverse con los conceptos ya definidos. Sus finalidades incitar a los } \\
\text { alumnos a poner a prueba sus ideas o estimular el interés por el tema presentando problemas que posteriormente justifican } \\
\text { una interpretación o un nuevo enfoque. Ejemplos: “¿Es beneficiosa o perjudicial la competencia intraespecífica para los } \\
\text { individuos que interaccionan? }\end{array}$ & I.A6 \\
\hline & & Identificación & Son pasajes explicativos que aluden a reconocer un objeto o proceso de la temática. & I.A7 \\
\hline & \multirow{4}{*}{$\begin{array}{l}\text { I.B. } \\
\text { Iconicidad }\end{array}$} & Fotografía & Fiel copia de la captura de cualquier imagen. & I.B1 \\
\hline & & Dibujo Figurativo & Prima la representación orgánica, mostrando los objetos mediante la imitación de la realidad. & I.B2 \\
\hline & & $\begin{array}{l}\text { Dibujo } \\
\text { Figurativo+Signos }\end{array}$ & Representaciones o magnitudes inobservables en un espacio de representación heterogéneo. & I.B3 \\
\hline & & $\begin{array}{l}\text { Dibujo } \\
\text { Esquemático }\end{array}$ & Esquematización sin similitud con elementos reales, donde prima la representación de las relaciones. & I.B4 \\
\hline
\end{tabular}




\section{Resultados}

Se registraron datos de 241 imágenes de ecosistema en los libros de texto, que se reflejan a través de una plantilla según la Tabla 3. En total se han identificado 477 UA, 92 UA en el Libro 1, 120 UA en el Libro 2, 180 UA en el Libro 3 y 85 UA en el Libro 4 (ver Gráfica 1).

Tabla 3

Ejemplo de plantilla para registro de datos sobre las imágenes en los libros de texto

\begin{tabular}{|c|c|c|c|c|}
\hline \multicolumn{5}{|c|}{ Plantilla registro de datos sobre imágenes en los libros de texto } \\
\hline Editorial & $\begin{array}{c}\mathrm{N}^{\circ} \text { de } \\
\text { Página }\end{array}$ & Función Didáctica & Iconicidad & Observaciones \\
\hline \multirow[t]{10}{*}{ Libro 1} & \multirow{4}{*}{220} & I.A7 Identificación & I.B1 Fotografia & \multirow{4}{*}{$\ldots / \ldots$} \\
\hline & & I.A3 Aplicación & I.B1 Fotografia & \\
\hline & & I.A3 Aplicación & I.B1 Fotografia & \\
\hline & & I.A3 Aplicación & I.B1 Fotografia & \\
\hline & \multirow{6}{*}{221} & I.A3 Aplicación & I.B1 Fotografia & \multirow{6}{*}{$\ldots / \ldots$} \\
\hline & & I.A3 Aplicación & I.B1 Fotografía & \\
\hline & & I.A3 Aplicación & I.B1 Fotografia & \\
\hline & & I.A3 Aplicación & I.B1 Fotografia & \\
\hline & & I.A3 Aplicación & I.B1 Fotografia & \\
\hline & & I.A3 Aplicación & I.B1 Fotografía & \\
\hline \multirow[t]{5}{*}{ Libro 2} & 72 & I.A2 Definición & I.B1 Fotografia & \multirow{2}{*}{$\ldots / \ldots$} \\
\hline & 12 & I.A6 Problematización & I.B1 Fotografia & \\
\hline & \multirow{3}{*}{81} & I.A6 Problematización & I.B2 Dibujo figurativo & \multirow{3}{*}{$\ldots / \ldots$} \\
\hline & & I.A6 Problematización & I.B4 Dibujo esquemático & \\
\hline & & I.A4 Descripción & I.B1 Fotografia & \\
\hline$\ldots / \ldots$ & $\ldots / \ldots$ & $\ldots / \ldots$ & $\ldots / \ldots$ & $\ldots / \ldots$ \\
\hline
\end{tabular}

Por otra parte, en la Gráfica 1 pretendemos resaltar las variables pertenecientes a la categoría de la función de la secuencia didáctica en que aparecen las imágenes en los libros de texto y las variables pertenecientes a la categoría de iconicidad, debido al valor agregado que hemos encontrado en ambas para la enseñanza y el aprendizaje del ecosistema.

La distribución del total de imágenes analizadas fue: 47, 60, 90 y 44 en los libros 1, 2, 3 y 4, respectivamente. Ante esto podemos decir que la categoría denominada función de la secuencia didáctica, que alude al papel que pretenden cumplir las imágenes en el libro de texto, tiene como representante mayoritario a la variable de I. A7 identificación en los cuatro libros de texto, siendo la I. A1 evocación la minoritaria. Particularizando, encontramos que las imágenes del libro 1 destacan en mayor medida la función I. A3 aplicación, papel que también se encuentra en el resto de los libros, pero en menor medida.

A su vez, encontramos que el libro 2 es el que presenta mayor número de imágenes que cumplen la función de I.A6 problematización, siendo el libro 4 el que evidencia en menor medida dicha función. En cuanto al libro 3 destaca sobre los demás en la función I. A7 identificación.

Respecto a la categoría de la iconicidad, entendiéndose como el grado de mayor similitud entre una imagen y lo que ésta pretende representar, es decir, que a mayor grado de iconicidad más acercamiento a la realidad, se encontró que los cuatro libros tienden en su mayor medida al uso de la 
I.B1 fotografía: 36, 29, 17 y 35 son la cantidad de imágenes de tipo fotográfico halladas en los libros 1, 2,3 y 4, respectivamente. Como antítesis encontramos para todos los libros una frecuencia minoritaria en la representación de I.B4 dibujo esquemático: 1, 4, 1 y 1 es la cantidad de imágenes en los libros $1,2,3$ y 4 , respectivamente.

Así mismo, se resalta que la I.B2 dibujo figurativo tiene un auge en el libro 3; este tipo de iconicidad, a pesar de que no se acerca tanto a la realidad como la fotografía, puede llegar a ser beneficiosa en algunos contextos de la enseñanza-aprendizaje.

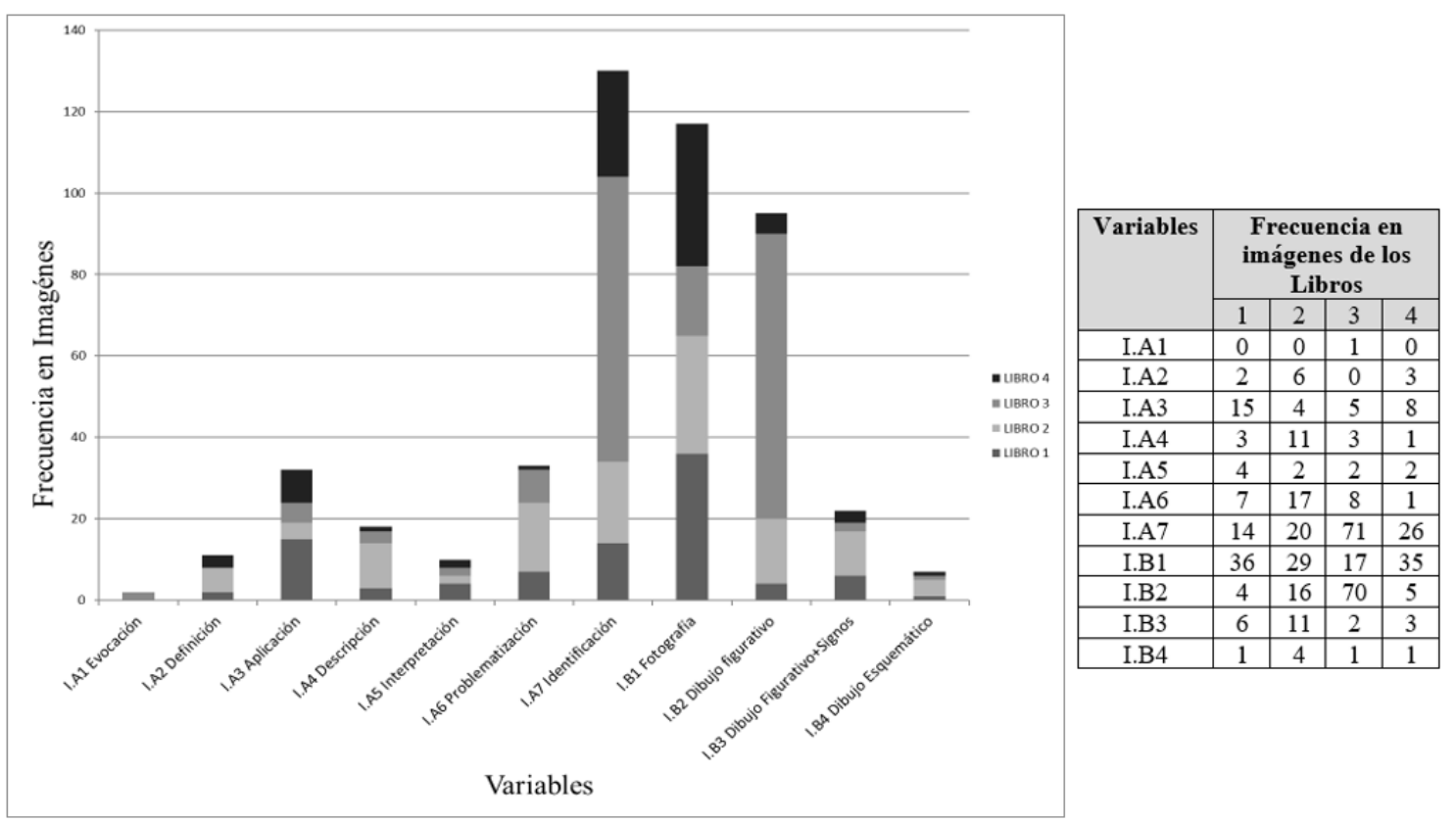

Gráfica 1. Variables de imágenes sobre ecosistema halladas en los libros de texto

A continuación, mostramos en la Figura 1 dos ejemplos de las imágenes que se analizaron como soporte de los resultados obtenidos. 


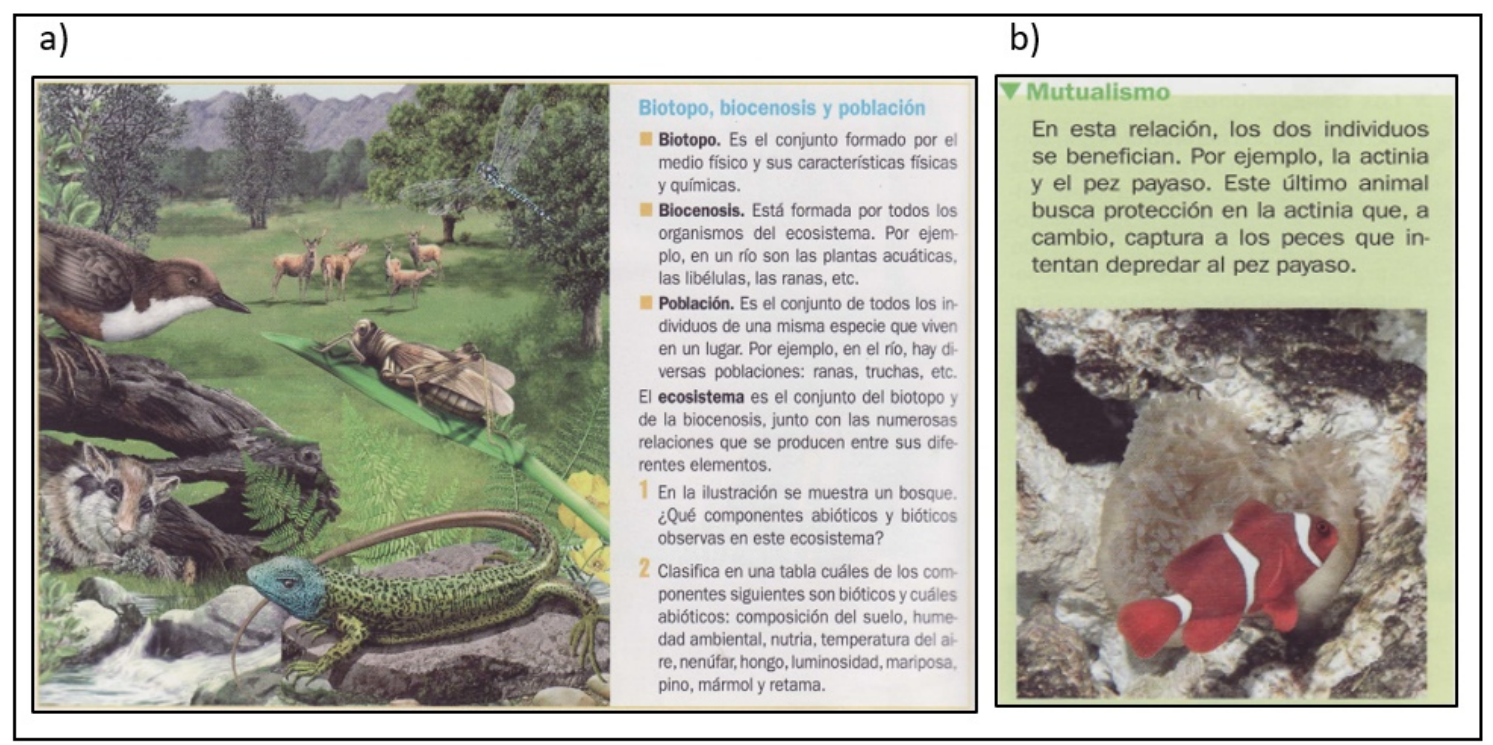

Figura 1. Ejemplos de imágenes analizadas en el Libro 1

Para la imagen "a" determinamos que la secuencia de la función didáctica es I. A2 definición, ya que establece el significado de varios términos con el contexto teórico. Igualmente, podría identificarse como una variable I.A6 problematización porque se plantean cuestiones. Sin embargo, descartamos la segunda porque sus preguntas están más bien enfocadas a reforzar la definición de conceptos. De las evidencias anteriores, aparece ambigüedad cuando intentamos conectar la variable I. A2 definición con un nivel de iconicidad como I.B2 dibujo figurativo, que es el representado en la imagen "a", nivel que consideramos poco idóneo a la hora de pretender definir conceptos, sobre todo cuando éstos suelen tener un carácter abstracto. En este caso sería beneficiosa la representación de otros códigos, por ejemplo, algunas flechas que indicaran magnitudes implícitas para facilitar la integración de la representación lingüística de la etiqueta con lo manifestado en el dibujo.

En el caso de la imagen " $b$ " determinamos que la secuencia de la función didáctica a la que pertenece es la de I.A3 aplicación, dado que constituye un ejemplo que extiende una explicación mediante la iconicidad de tipo I.B1 fotográfica (concurrencia altamente detectada en este estudio). Situación que hallamos idónea para la ejemplificación, ya que según Moles (1991) la imagen, al acercarse más a la realidad, posee menos códigos simbólicos, lo que ayuda a su interpretación.

Estos resultados reflejan que existen concurrencias favorables y otras menos eficaces para el aprendizaje del ecosistema, aspecto que nos permite afirmar que las editoriales han debido tener en cuenta algunas de las sugerencias que se han realizado en anteriores estudios como los de Perales y Jiménez (2002), situación que nos anima a continuar la ampliación de investigaciones en esta línea.

\section{Discusión}

De acuerdo a los resultados que acabamos de presentar, podemos establecer que las imágenes de los libros de texto analizadas desde el sistema de categorías aquí planteado permite determinar una dependencia entre la función didáctica y la iconicidad de las imágenes, vinculo que hemos estado denominando concurrencia. En este sentido, el nivel de iconicidad opera eficazmente debiendo guardar relación con las diferentes funciones didácticas que se pretenden utilizar en el aula. 
$\mathrm{Al}$ respecto mostramos las concurrencias representativas halladas en las imágenes del ecosistema: las imágenes de los libros 1, 2 y 4 reflejaron una relación bastante estrecha entre las variables I.A2 definición y I.B3 dibujo figurativo+signos, porque cuando las ilustraciones pretendieron establecer el significado de un término nuevo dentro de un contexto teórico se favoreció encontrar signos para aclarar relaciones dinámicas, como es el caso de imágenes que definían procesos. Concurrencia que ayudaría a aminorar la incomprensión sobre el flujo de energía en los ecosistemas que, como afirman García-Rodeja y Silva (2014), es una de las dificultades más representativas en los estudiantes.

Desvelamos que en los cuatro libros existe una alta correspondencia de ilustraciones que mostraron ejemplos para extender o consolidar una definición, mediante una iconicidad de alto nivel, como lo es la fotografía. Ello permitió concluir que, para ejemplificar (variable I.A3 aplicación) lo ideal es hacerlo a través de una imagen que se aproxime a lo real. Sin embargo, pensamos que dependiendo del concepto o temática que se quiera ejemplificar, otro de los niveles de iconicidad que se ajustaría a dicha variable es el I.B2 dibujo figurativo.

En este caso también podríamos concretar que la iconicidad empleada para las ilustraciones de los libros de texto, aunque dependa de la función de la secuencia didáctica, no es predecible que pueda facilitar la lectura de dichas ilustraciones porque pueden haber otras variables, como por ejemplo las etiquetas verbales, que también podrían ser coadyuvantes o no en la interpretación de la lectura de éstas. De ahí que vemos importante integrar el valor agregado (concurrencias) de las distintas variables que puede presentar una imagen con el acompañamiento del profesorado hacia sus estudiantes en la interpretación de las mismas (Velasco y Navarro, 2014). Además porque concordamos con Perales y Jiménez (2004) cuando afirman que las imágenes, como cualquier otra representación gráfica, no expresan nada en sí mismas, ya que son las personas las que determinan el significado en función de las concepciones y de sus necesidades de información.

Teniendo en cuenta lo discutido, consideramos relevante mostrar una última concurrencia hallada en los cuatro libros de texto, denominada múltiple, porque las imágenes de corte problematizador fueron representadas a través de diversos niveles de iconicidad, aspecto que consideramos factible. Dependiendo del nivel de complejidad que el profesor pretenda poner a prueba a sus estudiantes, se debe evaluar la opción de emplear un nivel icónico u otro.

Al respecto, comparando la I.A6 problematización con los diversos niveles de la I.B iconicidad obtenemos como resultante una alta concurrencia entre I.A6 problematización y I.B4 dibujo esquemático, dado que esta última variable no guarda similitud con elementos reales, primando la representación de las relaciones y facilitando que la imagen problematice al lector sin ofrecer muchos datos de conceptos que ya haya visto, pero pretendiendo llevarlo a una interpretación general de los mismos. Esto se aplica para el caso extendido de las representaciones gráficas o los mapas conceptuales, que suelen estar presentes en las pruebas o tests académicos, pero lamentablemente su interpretación presenta cierto grado de dificultad, donde uno de los posibles obstáculos se debe a que no se suele integrar el texto con la imagen, dejándolas simplemente como acompañantes al mismo en situación poco contribuyente al desarrollo de la alfabetización visual (Reyes et al., 2017).

De lo anterior, establecemos que de todos los libros, el 2 es el que representa en mayor medida imágenes problematizadoras desde una iconicidad esquemática y, por tanto, coopera en cierto modo a familiarizar a los lectores sobre pruebas académicas que puedan realizar en un futuro. Por otro lado, los libro 1, 3 y 4 usan en menor medida el dibujo esquemático, caso menos efectivo para la enseñanza y aprendizaje del ecosistema, ya que aquella es una representación que 
consideramos relevante, no solo para la preparación de las pruebas que incorporen este tipo de representaciones, sino porque guardan un carácter especial, ayudan en la síntesis de conceptos y en la abstracción de datos sin el requerimiento de conocimientos científicos específicos.

Finalmente, podemos considerar que coincidimos con Pereira y Romualdo (2017) cuando afirman lo importante de la conjugación de diferentes pictogramas para la aclaración de conceptos, por tanto, en este estudio podemos determinar que el libro 2 al ser el que representa diversos pictogramas de manera equiparada, posiblemente favorezca en mayor medida la enseñanza y el aprendizaje del ecosistema.

\section{Consideraciones finales e implicaciones didácticas}

Entendemos que las imágenes de los libros de texto pueden utilizarse para distintas tareas: evocar, definir, aplicar, describir, interpretar, problematizar e identificar, debido a su carácter polisémico, y que estas múltiples funciones que pretenden cumplir deben ser representadas bajo un nivel de iconicidad que no solo dependerá de la función, sino también de los meta-conceptos que quieran ser representados del ecosistema y, en especial, del propósito que el profesorado requiera.

Adicionalmente resaltamos que la dependencia entre la función didáctica y la iconicidad de las imágenes la consideramos como una concurrencia que reveló algunos fallos y beneficios en las representaciones pictóricas encontradas en los libros de este estudio. Vínculo que el profesorado debe conocer para concienciarse y optimizar el uso de éstas, logrando desde el desarrollo de competencias visuales una alfabetización científica del ecosistema.

Concretamente, a la luz de los hallazgos, se destaca que los cuatro libros de texto representan el ecosistema en las imágenes de manera frecuente como complemento informativo, identificando sus elementos, relaciones y procesos dinámicos propios de este. Nuestros resultados coinciden con estudios como los de López-Manjón y Postigo (2016) sobre el cuerpo humano. En este sentido, consideramos que el papel informativo de la imagen en los libros de texto puede ayudar en algunos procesos cognitivos del aprendizaje de los estudiantes, sin embargo consideramos importante que los libros representen de manera equilibrada las distintas funciones que aquella puede cumplir, facilitando al profesorado en cierto modo un uso meta-representacional, que según Pereira y Romualdo (2017), es necesario para aclarar los conceptos, en nuestro caso el del ecosistema. Estrategia que repercute a la vez en los estudiantes, potenciando en ellos, como afirman Eilam y Gilbert (2014), el desarrollo de las competencias meta-representacionales sobre el ecosistema.

En síntesis, este estudio no pretende dogmatizar la lectura de una imagen. Por el contrario, abre caminos invitando al profesorado al diseño y reconstrucción de materiales curriculares para la mejora de la enseñanza y el aprendizaje (Parcerisa, 1996; Velasco y Navarro, 2014).

Según los datos aportados en este estudio surgen diversas implicaciones didácticas referentes tanto a los docentes como a los estudiantes, que son quienes interactúan frecuentemente con las imágenes de los libros de texto, haciendo una llamada especial al profesorado, dado que es el puente determinante como mediador entre las imágenes y los estudiantes. En este sentido, sería deseable que aquel colectivo recibiera una formación fundamentada en los estándares de alfabetización visual de competencias en la educación superior, para ayudar en la superación de las dificultades que tienen los estudiantes, en este caso respecto a la caracterización del ecosistema, y desarrollaran fácilmente las competencias meta-representacionales que le permitirían, entre otras cuestiones: a) manejar distintas ejemplificaciones, recogiendo funciones que pueden cumplir las imágenes incluidas en los 
libros de texto, para mitigar la concentración única en las cadenas tróficas; b) se deberían utilizar imágenes que integren procesos como el ciclo de la materia y el flujo de energía, usando signos y símbolos que ayuden aclarar la conexión de éstos con la disminución de la biomasa; c) se hace necesario ampliar los dibujos esquemáticos en los libros de texto y emplearlos en mayor medida aplicados a situaciones del contexto para facilitar, por ejemplo, la comprensión del reciclado de nutrientes al pasar de formas orgánicas a inorgánicas; y d) los libros de texto deberían orientar al profesorado en la identificación de una iconicidad adecuada para aclarar procesos no perceptibles, como por ejemplo el flujo de energía.

Lo anterior conlleva por nuestra parte una reflexión, entendiendo ésta no como un acto inherente a la propia práctica educativa sino como una comprensión teórica de la misma, interpretando y comprendiendo que muchas de las dificultades del aprendizaje del ecosistema pueden ser reforzadas en las clases desde las imágenes de los libros de texto pero que pueden ser superadas con su adecuada utilización.

\section{Referencias}

Álzate, M.V. (1999). ¿Cómo Leer un Texto Escolar? Texto, Paratexto e imágenes. Revista de Ciencias Humanas, 6 (20), 114-122.

Artola, E.C., Mayoral, L.E. y Benarroch, A. (2016). Dificultades de aprendizaje de las representaciones gráficas cartesianas asociadas a biología de poblaciones en estudiantes de educación secundaria. Un estudio semiótico. Revista Eureka sobre Enseñanza y Divulgación de las Ciencias, 13 (1), 36-52.

Bravo Torija, B. y Jiménez Aleixandre, M.P. (2010). ¿Salmones o sardinas? Una unidad para favorecer el uso de pruebas y la argumentación en ecología. Alambique, 63, 19-25.

Bravo Torija, B. y Jiménez Aleixandre, M.P. (2014). Articulación del uso de pruebas y el modelo de flujo de energía en los ecosistemas en argumentos de alumnado de bachillerato. Enseñanza de las Ciencias, 32 (3), 425-442.

Catley, K.M., Novick, L.R. y Shade, C.K. (2010). Interpreting Evolutionary Diagrams: When Topology and Process Conflict. Journal of Research in Science Teaching, 47 (7), 861-882.

Del Carmen, L.M. (2010). El estudio de los ecosistemas. Alambique, 66, 28-34.

Domingo-Martínez, A y Jiménez-Pérez, R. (2014). Influencia del contexto para el aprendizaje de conceptos complejos. El caso del ecosistema. En M.A. de las Heras, A.A. Lorca Marín, B. Vázquez Bernal, A. Wamba Aguado y R. Jiménez Pérez (Coord). Investigación y transferencia para una educación en ciencias. Un reto emocionante. 26 Encuentros de didáctica de las ciencias experimentales, (pp. 958-967). Huelva: Universidad de Huelva

Eilam, B. y Gilbert, J.K. (2014). The Significance of Visual Representations in the Teaching of Science. En B. Eilam y J.K Gilbert. (Eds). Science Teachers' Use of Visual Representations, (pp.328). Nueva York: Springer.

Fanaro, M.A., Otero, M.R. y Greca, I.M. (2005). Las imágenes en los materiales educativos: las ideas de los profesores. Revista Electrónica de Enseñanza de las Ciencias, 4 (2), 1-24.

García-Rodeja, I. y Silva, E. (2014). ¿Son capaces los estudiantes de aplicar conceptos clave sobre el funcionamiento de los ecosistemas?. En XXVI Encuentros de Didáctica de las Ciencias Experimentales, (pp. 498-505). Huelva. 
González, P., Vildósola, X. y Gine, N. (2012). Percepción del estudiantado de Enseñanza Secundaria Obligatoria acerca de la utilización de la imagen en clases de biología: estudio exploratorio con grupo de discusión. En Actas XXV Encuentros de Didáctica de las Ciencias Experimentales, (pp. 407-414). Santiago de Compostela.

Lazarowitz, R. (2014). High school biology curricula development. Implementation, teaching, and evaluation from the 20 th the 21 st century. En N.G Lederman y S.K Abel (Eds). Handbook of Reasearch on Science Education (pp. 412-333). Nueva York y Londres: Routledge Taylor and Francis Group.

Lee, V. (2010). Adaptations and continuities in the use and design of visual representations in US Middle School science textbooks. International Journal of Science Education, 32 (8), 1099-1126.

Lopes, L. y Rocha, C. (2008). Percepção e educação ambiental sobre o ecossistema manguezal incrementando as disciplinas de ciências e biologia em escola pública do recife-pe. Investigações em Ensino de Ciências, 13(1), 79-93.

López-Manjón, A. y Postigo, Y. (2014) Análisis de las imágenes del cuerpo humano en libros de texto españoles de primaria. Enseñanza de las Ciencias, 32 (3), 551-570.

López-Manjón, A. y Postigo, Y. (2016). ¿Qué libro de texto elegir? La competencia visual en las actividades con imágenes. Revista Eureka sobre Enseñanza y Divulgación de las Ciencias, 13 (1), 84101.

López, F.J. y Travé, G. (2013). Materiales curriculares de elaboración propia en Internet. ¿Una alternativa al libro de texto para el área de conocimiento del medio? Edutec. Revista Electrónica de Tecnología Educativa, 44, 1-13.

Lowe, R. (2000). Alfabetismo visual y educación científica y tecnológica. Boletín internacional de la Unesco de educación cientifica, tecnológica y ambiental, 25 (2), 1-3.

Moles, A. (1991). Pensar en línea, pensar en superficie. En J. Costa, y A. Moles (Eds.). Imagen Didáctica. Enciclopedia del Diseño (pp. 9-35). Barcelona: Ceac.

Mampel, L., Cortés, A.L. y Alcalá, L. (2015). Imágenes sobre dinosaurios en libros de texto de Enseñanza Secundaria Obligatoria. Didáctica de las Ciencias Experimentales y Sociales, 29, 173 193 DOI: 10.7203/DCES.29.4312

Parcerisa, A. (1996). Materiales curriculares. Cómo elaborarlos, seleccionarlos y usarlos. Barcelona: Graó. Biblioteca de Aula.

Perales, F.J. y Jiménez, J.D. (2002). Las ilustraciones en la enseñanza-aprendizaje de las ciencias. Análisis de libros de texto. Enseñanza de las Ciencias, 20(3), 369-386.

Perales, F.J. y Jiménez, J.D. (2004). Las ilustraciones en los libros de Física y Química de la ESO. En J.J. Gil (Coord.). Aspectos didácticos de Física y Química (pp.11-65). I.C.E. de la Universidad de Zaragoza.

Perales, F.J. (2006). Uso y abuso de la imagen en la enseñanza de las ciencias. Enseñanza de las Ciencias, 24(1), 13-30.

Perales, F.J. y Vílchez, J. (2012). Libros de texto: Ni contigo ni sin ti tienen mis males remedios. Alambique, 70, 75-82.

Perales, F.J. y Vílchez, J.M. (2015). Iniciación a la investigación educativa con estudiantes de secundaria: el papel de las ilustraciones en los libros de texto de ciencias. Enseñanza de las Ciencias, 33 (1), 243-262. 
Pereira, G. y Romualdo, C. (2017). Representações pictóricas em manuais escolares de geologia do ensino secundário: um estudo no âmbito do paleomagnetismo. Revista Brasileira de Pesquisa em Educação em Ciências, 17 (2), 365-382.

Pozzer, L.L. y Roth, W.M. (2003). Prevalence, Function, and Structure of Photographs in High School Biology Textbooks. Journal of Research in Science Teaching, 40 (10), 1089-1114.

Postigo, Y. y López, A. (2012). Students' Conceptions of Biological Images as Representational Devices. Revista colombiana de psicología, 21 (2), 265-284.

Reyes, J.R., García, B. y Mateos, A. (2017). Visual Literacy in Preservice Teachers: a Case Study in Biology. Research in Science Education, 1-23, doi: 10.1007/s11165-017-9634-2

Rincón, M. (2011). Concepciones de los estudiantes sobre educación básica sobre ecosistema. Una revisión documental. Bio-grafía: escritos sobre la biología y su enseñanza, 4 (2), 77-93.

Rodríguez, F., De las Heras, M.A., Romero, R. y Cañal, P. (2014). El conocimiento escolar sobre los animales y las plantas en primaria: Un análisis del contenido específico en los libros de texto. Revista Electrónica de Enseñanza de las Ciencias, 13(1), 97-114.

Ruppenthal, R. y Chitolina, M.R. (2014). The respiratory system in science textbooks in initial grades: analysis of the content, images and activities. Ciência \& Educaçao, Bauru, 19 (3), 617632.

Tapia, F. y Arteaga, Y. (2012). Selección y manejo de ilustraciones para la enseñanza de la célula: Propuesta Didáctica. Enseñanza de las Ciencias, 30 (3), 281-294.

Travé, G.; Estepa, J. y Delval, J. (2017). Análisis de la fundamentación didáctica de los libros de texto de conocimiento del medio social y cultural. Educación XXI, 20(1), 319-338, doi: $10.5944 /$ educXX1.11831

Velasco, S. y Navarro, M. (2014). El papel de la imagen en la enseñanza. Análisis de las ilustraciones del proceso de la meiosis en fuentes de consulta utilizadas por alumnos de Biología del CCH Vallejo. Nuevos Cuadernos del Colegio, 3, 1-33.

Waldrip, B. y Prain, V. (2012). Learning from and through representations in science. En B.J. Fraser, K.G. Tobin y C.J. McRobbie (Eds.). Second International Handbook of Science Education (pp.145155). Dordrecht, Heidelberg, London y New York: Springer.

\section{Información sobre los autores}

Autor: Linda Arelis Silva Arias

Institución: Departamento de didácticas integradas. Facultad de Ciencias de la Educación. Universidad de Huelva.

E-mail: linda.silva@alu.uhu.es

Información biográfica: Doctoranda en Investigación en la enseñanza y el aprendizaje de las ciencias experimentales, sociales, matemáticas y de la actividad física y deportiva de la Universidad de Huelva. 
Autor: Roque Jiménez Pérez

Institución: Departamento de didácticas integradas. Facultad de Ciencias de la Educación. Universidad de Huelva.

E-mail: rjimenez@uhu.es

Información biográfica: Doctor en Ciencias Químicas por la Universidad de Sevilla. Catedrático de Didáctica de las Ciencias Experimentales de la Facultad de Ciencias de la Educación de la Universidad de Huelva. 


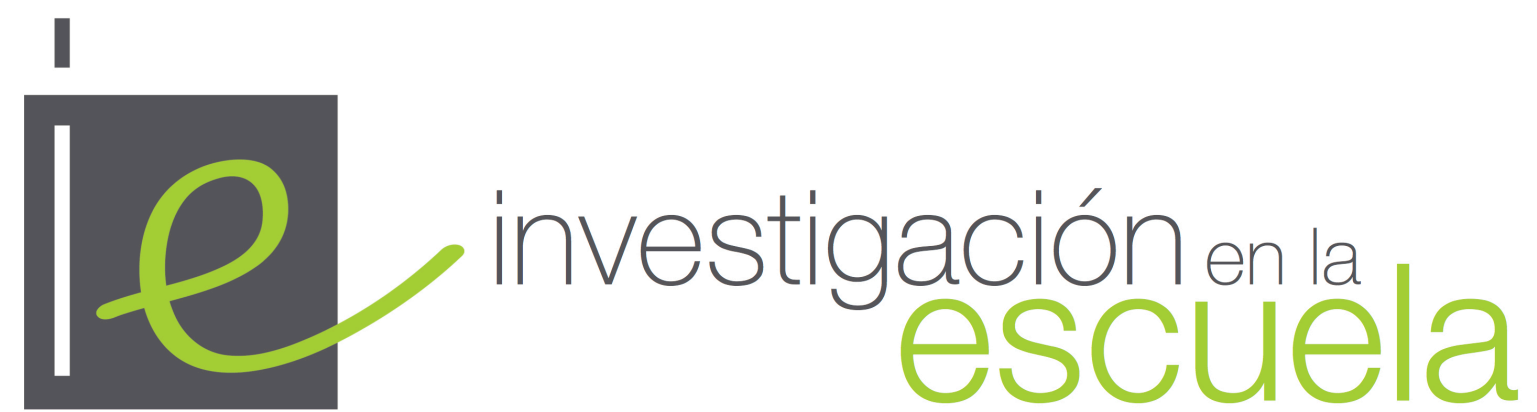

Revista académica evaluada por pares y de acceso abierto

Número 93

28 de diciembre de 2017

ISSN 2443-9991

\begin{abstract}
(c)
SOMEREIGHISRESERVEDLOS/as lectores/as pueden copiar, mostrar, y distribuir este artículo, siempre y cuando se de crédito y atribución al autor/es y a Investigación en la Escuela, se distribuya con propósitos no-comerciales, no se altere o transforme el trabajo original. Más detalles de la licencia de CreativeCommons se encuentran en http://creativecommons.org/licenses/by-nc-sa/3.0 Cualquier otro uso debe ser aprobado en conjunto por el autor/es, o Investigación en la Escuela.
\end{abstract}

पiv?

Revista Editada por la Universidad de Sevilla. https://editorial.us.es/es/revistainvestigacion-en-la-escuela

Contribuya con comentarios y sugerencias en la web de la revista. Por errores y sugerencias contacteasecretaria@investigacionenlaescuela.es 


\section{Investigación en la escuela}

Consejo de dirección: Ana Rivero García (Universidad de Sevilla), Nicolás de Alba Fernández (Universidad de Sevilla), Pedro Cañal de León (Universidad de Sevilla), Francisco F. García Pérez (Universidad de Sevilla), Gabriel Travé González (Universidad de Huelva), Francisco F. Pozuelos Estrada (Universidad de Huelva)

Dirección: Ana Rivero García y Nicolás de Alba Fernández

Secretaría de edición: Elisa Navarro Medina

\section{Consejo editorial}

José Félix Angulo Rasco. Universidad de Cádiz Rosa Má Ávila Ruiz. Universidad de Sevilla Pilar AzcárateGoded. Universidad de Cádiz Juan Bautista Martínez Rodríguez. Universidad de Granada

Nieves Blanco García. Universidad de Málaga Fernando Barragán Medero. Universidad de La Laguna José Carrillo Yáñez. Universidad de Huelva José Contreras Domingo. Universidad de Barcelona. Luis C. Contreras González. Universidad de Huelva Ana $\mathbf{M}^{\mathbf{a}}$ Criado García-Legaz. Universidad de Sevilla Rosario Cubero Pérez. Universidad de Sevilla José $\mathbf{M}^{\mathbf{a}}$ Cuenca López. Universidad de Huelva Jesús Estepa Giménez. Universidad de Huelva Rafael Feito Alonso. Universidad Complutense (Madrid)

Francisco José García Gallardo. Universidad de Huelva

Soledad García Gómez. Universidad de Sevilla J. Eduardo García Díaz. Universidad de Sevilla
Fernando Hernández Hernández. Universidad de Barcelona

Salvador Llinares Ciscar. Universidad de Alicante Alfonso Luque Lozano. Universidad de Sevilla Rosa Martín del Pozo. Universidad Complutense (Madrid)

José Martín Toscano. IES Fernando Herrera (Sevilla) Jaume Martínez Bonafé. Universidad de Valencia F. Javier Merchán Iglesias. Universidad de Sevilla Emilia Moreno Sánchez. Universidad de Huelva. Rosario Ortega Ruiz. Universidad de Córdoba Antonio de Pro Bueno. Universidad de Murcia Fco. de Paula Rodríguez Miranda. Universidad de Huelva

Pedro Sáenz-López Buñuel. Universidad de Huelva Antoni Santisteban Fernández. Universidad Autónoma (Barcelona)

Emilio Solís Ramírez. Catedrático de IES. $\mathbf{M}^{\mathbf{a}}$ Victoria Sánchez García. Universidad de Sevilla. Magdalena Suárez Ortega. Universidad de Sevilla

\section{Consejo asesor}

Manuel Área Moreira. Universidad de La Laguna

Jaume Carbonell. Director Cuadernos de Pedagogía. Barcelona

César Coll. Universidad de Barcelona

Christopher Day. Universidad de Nothingham. U.K.

Juan Delval. Universidad Nacional de Educación a Distancia

John Elliott. Universidad de East Anglia. Norwich. U.K.

José Gimeno Sacristán. Universidad de Valencia

André Giordan. Universidad de Paris VII y Ginebra

Francisco Imbernón. Universidad de Barcelona

Ángel Pérez Gómez. Universidad de Málaga

Rafael Porlán Ariza. Universidad de Sevilla

Francesco Tonucci. Instituto de Pedagogía del C.N.R. Roma

Jurjo Torres Santomé. Universidad de A Coruña 
